\title{
Bradykinin prevents the apoptosis of NIT-1 cells induced by TNF- $\alpha$ via the PI3K/Akt and MAPK signaling pathways
}

\author{
XIZHEN XU, LING TU, WEI JIANG, WENJING FENG, CHUN XIA ZHAO and DAO WEN WANG \\ Department of Internal Medicine and The Institute of Hypertension, Tongji Hospital, Tongji Medical \\ College of Huazhong University of Science and Technology, Wuhan 430030, P.R. China
}

Received December 22, 2011; Accepted January 30, 2012

DOI: $10.3892 / \mathrm{ijmm} .2012 .922$

\begin{abstract}
The kallikrein-kinin system (KKS) is a complex multi-enzyme system which is composed of circulating and tissue kallikrein and kinin. It is well established that tissue kallikrein and kinin play crucial and diverse roles in cardiovascular and renal homeostasis. Recent data indicate that kallikrein gene delivery reduces insulin resistance in STZ-treated rats suggesting a protective role for kinin in the development of diabetes. This study investigated the effects of exogenous bradykinin (BK) on the apoptosis of NIT-1 cells, a pancreatic $\beta$-cell line in vitro. Exogenous BK significantly protected NIT-1 cells from TNF- $\alpha$-induced apoptosis. These effects were associated with upregulation of Bcl-2 and Bcl-xL protein expression levels as well as with downregulation of Bax expression levels via the activation of the mitogenactivated protein kinase and PI3K/Akt signaling pathways. In conclusion, these data highlight the beneficial roles of $\mathrm{BK}$ on pancreatic $\beta$-cell function.
\end{abstract}

\section{Introduction}

The kallikrein-kinin system (KKS) is a complex multi-enzyme system which is composed of a circulating and a tissue KKS. The circulating KKS plays critical roles in coagulation and fibrinolysis, whereas the tissue KKS acts in a paracrine or autocrine fashion involving the local synthesis and release of kinins, such as bradykinin and kallidin, mainly from kininogens by the kininogenase, tissue kallikrein (1). It has been well established that the KKS plays a crucial and diverse role in physiological effects, such as pain, inflammation, hypotension, edema formation, and smooth muscle contraction (2). Bradykinin receptors are mainly divided pharmacologically into two subtypes, B1 and B2. Previous data indicate that most of the known actions of bradykinin $(\mathrm{BK})$ are mediated via $\mathrm{B} 2$

Correspondence to: Dr Dao Wen Wang, Department of Internal Medicine, Tongji Hospital, Tongji Medical College, Huazhong University of Science and Technology, Wuhan 430030, P.R. China

E-mail: dwwang@tjh.tjmu.edu.cn

Key words: bradykinin, apoptosis, NIT-1, TNF- $\alpha$ receptors. Bradykinin $\mathrm{B} 2$ receptor couples to mainly heterotrimeric G-protein, the Gq subfamily; Gi and Gs subfamilies are also reported to couple bradykinin receptors in some cell types (3).

Obesity and type 2 diabetes are a worldwide epidemic associated with significant morbidity and mortality. People with diabetes have higher all-cause mortality rates than those without diabetes. Type 2 diabetes is characterized by reduced insulin sensitivity attributed to insulin resistance and pancreatic $\beta$-cell dysfunction. Increasing evidence indicates that the kallikrein and bradykinin system exert important roles in energy metabolism and homeostasis. Tissue kallikrein levels are increased in type 2 diabetic patients, whereas no differences have been noted in circulating levels of bradykinin and kallidin peptides, and high and low molecular weight kininogens (4). In addition, lack of B1 and B2 receptor exacerbates diabetic complications (5). Human tissue kallikrein gene delivery reduces hyperinsulinemia in fructose-induced hypertensive rats, indicating that human tissue kallikrein may have potential as a treatment for hypertension and associated insulin resistance (6). In addition, it has been demonstrated that human tissue kallikrein gene delivery can efficiently attenuate hypertension, insulin resistance, and diabetic nephropathy in streptozotocin-induced diabetic rats. These data suggest that kallikrein and bradykinin may be a potential target for the therapy of diabetes (7). However, the effect of the kallikrein and bradykinin system on islet survival remains unclear. In the present study, we used cultured cells to investigate whether BK is involved in the prevention of $\beta$-cell apoptosis in vitro.

\section{Materials and methods}

Materials and reagents. Annexin V and propidium iodide (PI) apoptosis detection kits were purchased from Nanjing KeyGen Biotech Co., Ltd. (Nanjing, China). The caspase-3 colorimetric assay was obtained from R\&D Systems, Inc. (Minneapolis, $\mathrm{MN})$. Polyclonal and monoclonal antibodies against $\beta$-actin, phosphoinositide 3-kinase (PI3K), AKT, phosphorylated AKT (P-AKT), mitogen-activated protein kinase (MAPK), phosphorylated MAPK (P-MAPK), Bcl-2, Bcl-xL and Bax were obtained from Santa Cruz Biotechnology, Inc. (Santa Cruz, CA). Secondary antibodies (goat anti-rabbit and goat anti-mouse horseradish peroxidase-conjugated secondary antibodies) were from Sigma-Aldrich (St. Louis, MO). Bradykinin (BK), 

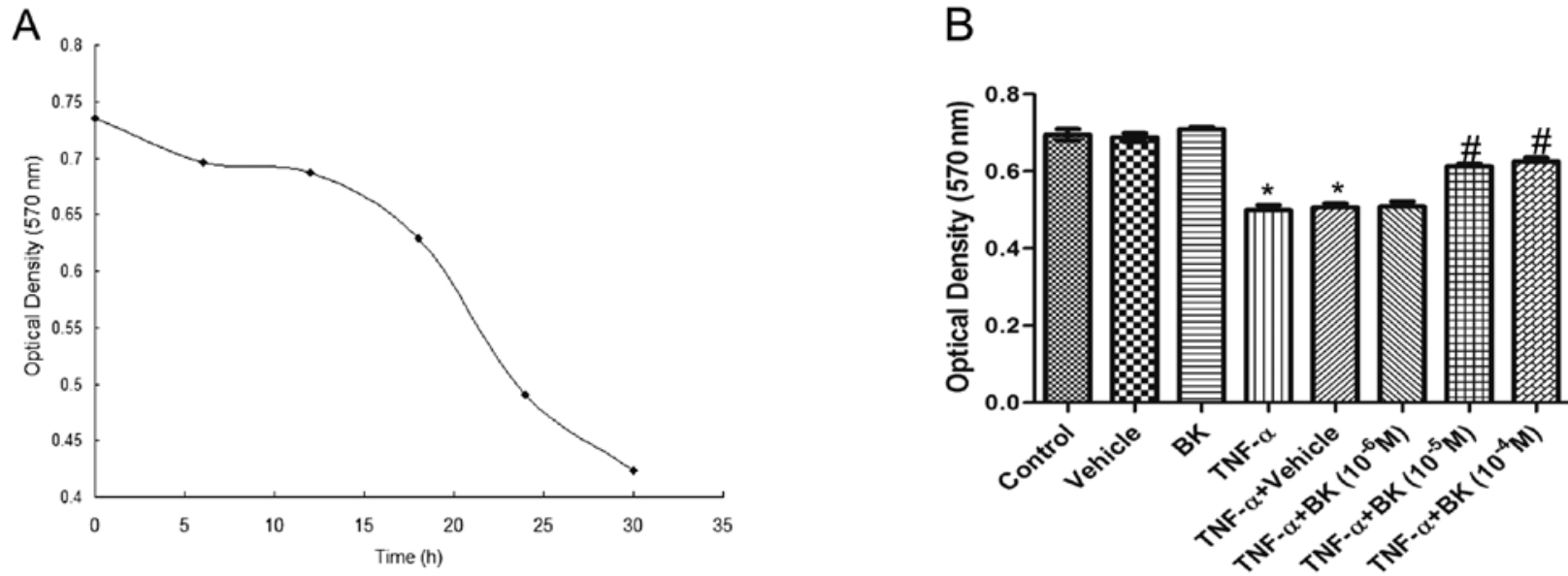

Figure 1. Exogenous bradykinin (BK) attenuates the TNF- $\alpha$-induced decrease in NIT-1 cells viabilty. (A) Time course of TNF- $\alpha$ on NIT-1 cell viability: NIT-1 cells were treated with TNF- $\alpha(100 \mathrm{ng} / \mathrm{ml})$. (B) The effects of different levels of bradykinin on NIT-1 cell viability: NIT-1 cells were treated with/without $1 \%$ glacial acetic acid (BK vehicle), TNF- $\alpha(100 \mathrm{ng} / \mathrm{ml})$, BK $\left(10^{-6} \mathrm{M}\right)$, BK $\left(10^{-5} \mathrm{M}\right)$ and BK $\left(10^{-4} \mathrm{M}\right)$ for $24 \mathrm{~h}$, then assayed by the sulforhodamine B (SRB) assay. Values are the mean \pm SEM from three independent experiments. ${ }^{*} \mathrm{P}<0.05$ vs. control; ${ }^{*} \mathrm{P}<0.05$ vs. TNF- $\alpha$.

HOE-140, Tween-20, phenylmethylsulfonyl fluoride, aprotinin, and sulforhodamine B (SRB), TNF- $\alpha$, PD98059, apigenin and LY294002 were from Sigma-Aldrich. All other chemicals and reagents were purchased from Sigma-Aldrich unless otherwise specified.

Cell culture. NIT-1 cells, a pancreatic $\beta$-cell line from transgenic NOD/Lt mice, were purchased from ATCC (Manassas, VA), and grown in Dulbecco's modified Eagle's medium (DMEM) supplemented with $5 \mathrm{mM} \mathrm{L}$-glutamine, $10 \% \mathrm{FBS}$, and an antibiotic mixture of $100 \mathrm{U} / \mathrm{ml}$ penicillin and $100 \mu \mathrm{g} / \mathrm{ml}$ streptomycin. NIT-1 cells were seeded on 6-, 12-, 24- or 96-well plates for the various experiments indicated in this study.

Viability assay of NIT-1 cells. NIT-1 cells were seeded into 96-well plates in triplicate and placed in media with reduced serum $(0.5 \%)$ for $12 \mathrm{~h}$ after cell attachment. NIT-1 cells apoptosis was induced by TNF- $\alpha(100 \mathrm{ng} / \mathrm{ml})$, and different action times of TNF- $\alpha$ were observed to determine the time course for the TNF- $\alpha$-induced decrease of NIT-1 cells viability. In order to identify the proper concentration of BK, different concentrations of BK $\left(10^{-6}, 10^{-5}\right.$ and $\left.10^{-4} \mathrm{M}\right)$ were added to the cells to observe the possible protective role on NIT-1 cells viability. HOE-140 $\left(10^{-5} \mathrm{M}\right)$, a bradykinin B2 receptor inhibitor, was added to clarify the possible BK receptor involved. NIT-1 cell viability was assessed via sulforhodamine B (SRB) assays, according to the manufacturer's protocol. Briefly, $50 \mu 1$ of $10 \%$ trichloroacetic acid was added to fixed cells at $4^{\circ} \mathrm{C}$ for $2 \mathrm{~h}$, after which the cells were stained with $70 \mu \mathrm{l}$ of $0.3 \%$ SRB for $30 \mathrm{~min}$. Color was developed with $200 \mu 1$ Tris base (10 mM; pH 10.5) and absorption at $570 \mathrm{~nm}$ was determined for each well using a microplate reader (BioTek Instruments, Winooski, VT).

Flow cytometry analysis for NIT-1 apoptosis. The effect of BK on NIT-1 cell apoptosis was studied using flow cytometry analysis. NIT-1 cells were seeded into 12-well plates in triplicate in reduced serum and treated with BK $\left(10^{-5} \mathrm{M}\right)$ in the presence and absence of HOE-140 $\left(10^{-5} \mathrm{M}\right)$, PD98059 (MEK inhibitor, $20 \mu \mathrm{M}$ ) and LY294002 (PI3K inhibitor, $15 \mu \mathrm{M}$ ). After

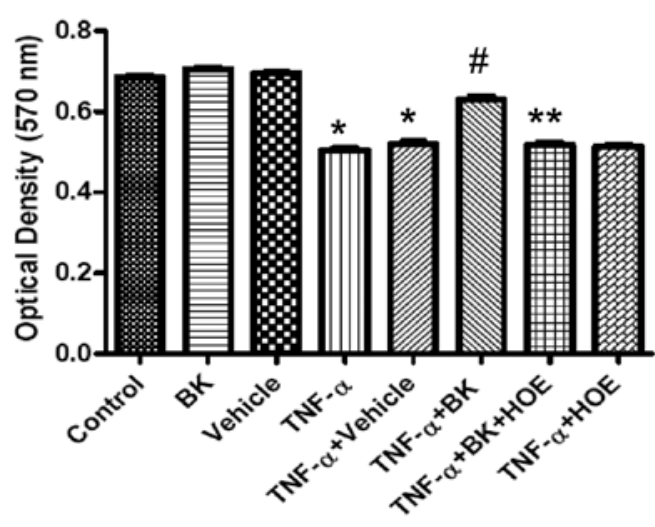

Figure 2. BK B2 receptor antagonist HOE-140 blocked the protective effects of BK on NIT- 1 cell viability decrease induced by TNF- $\alpha$. NIT-1 cells were treated with/without $1 \%$ glacial acetic acid (BK vehicle), TNF- $\alpha(100 \mathrm{ng} / \mathrm{ml})$, BK $\left(10^{-5} \mathrm{M}\right)$ and HOE-140 $\left(10^{-5} \mathrm{M}\right)$ for $24 \mathrm{~h}$, then assayed by SRB. Values are the mean \pm SEM from three independent experiments. ${ }^{*} \mathrm{P}<0.05$ vs. control; ${ }^{\#} \mathrm{P}<0.05$ vs. TNF- $\alpha$; ${ }^{* *} \mathrm{P}<0.05$ vs. TNF- $\alpha+\mathrm{BK}$.

$6 \mathrm{~h}, \mathrm{TNF}-\alpha(100 \mathrm{ng} / \mathrm{ml})$ was incubated with the cells for $24 \mathrm{~h}$ to induce apoptosis. After the incubation, cells were harvested and stained with Annexin V and PI for flow cytometry analysis according to the manufacturer's instructions. The ratio of cells that were Annexin V positive and PI negative (i.e. early apoptotic) was compared among the different treatment groups.

Caspase-3 activity assay for NIT-1 apoptosis. NIT-1 cells were seeded into 12-well plates in triplicate in reduced serum and treated with BK $\left(10^{-5} \mathrm{M}\right)$ in the presence and absence of HOE-140 $\left(10^{-5} \mathrm{M}\right)$, PD98059 $(20 \mu \mathrm{M})$ and LY294002 $(15 \mu \mathrm{M})$. After $6 \mathrm{~h}, \mathrm{TNF}-\alpha(100 \mathrm{ng} / \mathrm{ml})$ was added to the cells for $24 \mathrm{~h}$ to induce apoptosis, after which the cells were harvested. Caspase-3 activity was measured with a colorimetric assay kit using DEVD-p-nitroanilide as a substrate according to the manufacturer's instructions as described previously.

Western blot analysis. Cell proteins were extracted as previously described (8). Briefly, the cells were gently washed three 


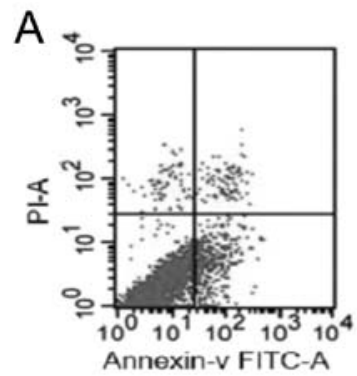

Control

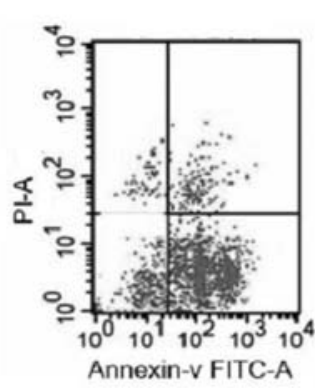

TNF- $\alpha+$ Vehicle

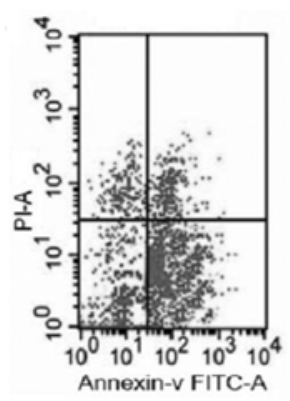

TNF- $\alpha+H O E-140$

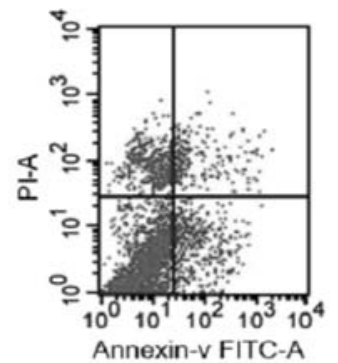

Vehicle

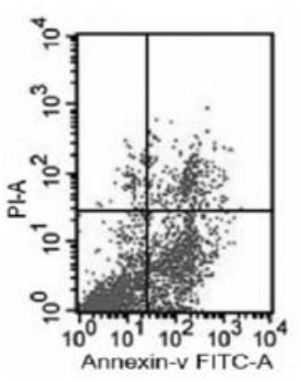

TNF- $\alpha+B K$

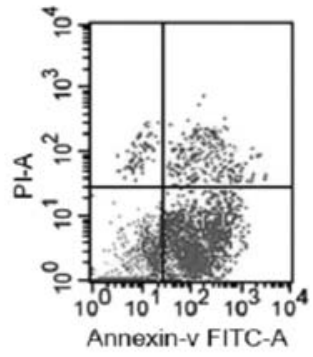

TNF- $\alpha$

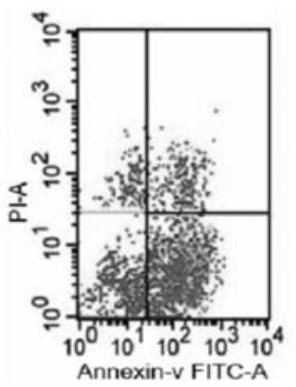

TNF- $\alpha+B K+H O E-140$

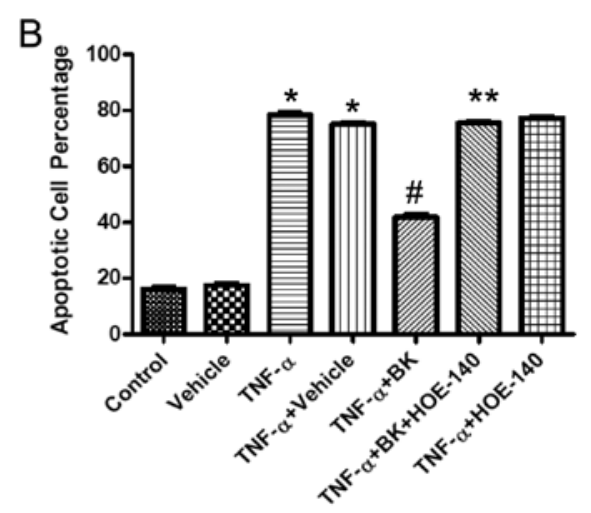

Figure 3. Exogenous BK attenuated TNF- $\alpha$ induced apoptosis. (A) Representative results from three independent experiments evaluating TNF- $\alpha$-induced apoptosis by Annexin V-FITC/propidium iodide (PI) staining and flow cytometry. NIT-1 cells were treated with/without $1 \%$ glacial acetic acid (BK vehicle), TNF- $\alpha$ (100 ng/ml), BK $\left(10^{-5} \mathrm{M}\right)$ and HOE-140 $\left(10^{-5} \mathrm{M}\right)$ for $24 \mathrm{~h}$, then stained with PI and Annexin V. Cells with PI-negative and Annexin V-positive staining are in the early stages of apoptosis. Cells with PI-positive and Annexin V-positive staining are in the late stages of apoptosis. (B) Quantification of the ratio of apoptotic to total cells in panel A. Values are the mean \pm SEM from three independent experiments. ${ }^{*} \mathrm{P}<0.05$ vs. control; ${ }^{\#} \mathrm{P}<0.05$ vs. TNF- $\alpha$; ${ }^{* *} \mathrm{P}<0.05$ vs. TNF- $\alpha+\mathrm{BK}$.

times with cold $1 \mathrm{X}$ PBS and homogenized in lysis buffer (500 mM Tris-Cl, $\mathrm{pH} 8.0,150 \mathrm{mM} \mathrm{NaCl}, 0.02 \%$ sodium azide, $0.1 \%$ SDS, $100 \mu \mathrm{g} / \mathrm{ml}$ phenylmethylsulfonyl fluoride, $1 \mu \mathrm{g} / \mathrm{ml}$ aprotinin, $1 \%$ Nonidet P-40, and $0.5 \%$ sodium deoxycholate). After incubation on ice for $30 \mathrm{~min}$, the lysate was centrifuged at $12,000 \mathrm{x}$ g at $4^{\circ} \mathrm{C}$ for $10 \mathrm{~min}$. The protein concentration of the supernatant was determined using the Bradford method. Twenty micrograms of protein were loaded onto $10 \%$ SDS/PAGE gels and electrophoretically transferred to PVDF membranes. Membranes were then probed using various antibodies and the ECL system was used to visualize the separated proteins. Blots were stripped and re-probed with $\beta$-actin as a loading control. Expression was quantified by densitometry and normalized to $\beta$-actin expression. All groups were then normalized to their respective controls as previously described (9).

Statistical analysis. All data are expressed as the means \pm SEM. Comparisons between groups were performed by a one-way analysis of ANOVA with post hoc analyses performed using the Student-Newman-Keuls method. $\mathrm{P}<0.05$ was indicative of statistically significant differences.

\section{Results}

Exogenous BK attenuates the TNF- $\alpha$-induced decrease in NIT-1 cell viabilty. To determine the time point at which TNF- $\alpha$ significantly decreased NIT-1 cell viability, NIT-1 cells were incubated with TNF- $\alpha(100 \mathrm{ng} / \mathrm{ml})$ for increasing durations, and NIT-1 cell viability was determined by the SRB assay.

As expected, TNF- $\alpha$ markedly decreased NIT-1 cell viability, and this decrease was time-dependent (Fig. 1A). Incubation with TNF- $\alpha$ for $24 \mathrm{~h}$, significantly reduced NIT-1 cells viability. We thus considered $24 \mathrm{~h}$ as a proper time point for viability decrease induction of NIT-1 cells, and used this time point in the subsequent experiments. 


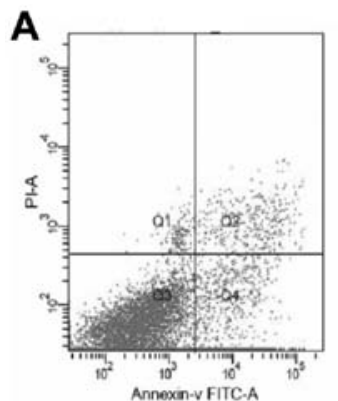

Control

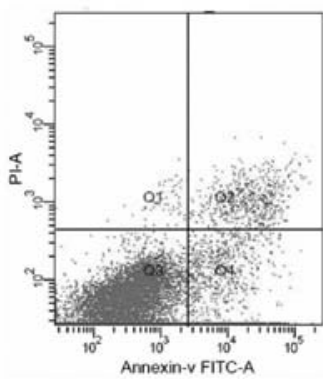

LY294002

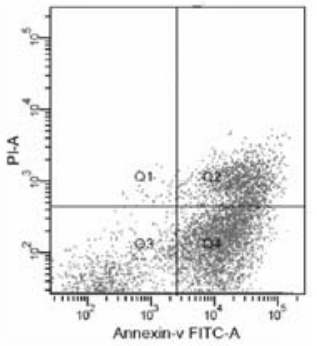

TNF- $\alpha+L Y 294002$

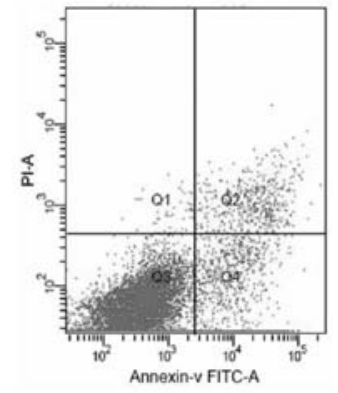

Vehicle

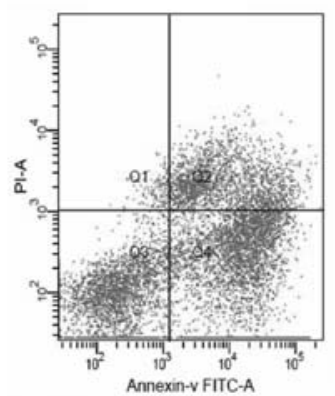

TNF- $\alpha$

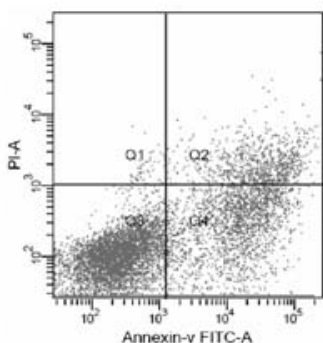

TNF- $\alpha+B K$

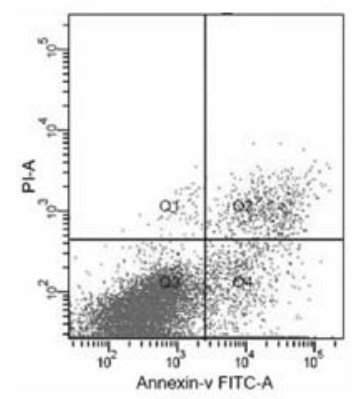

PD98059

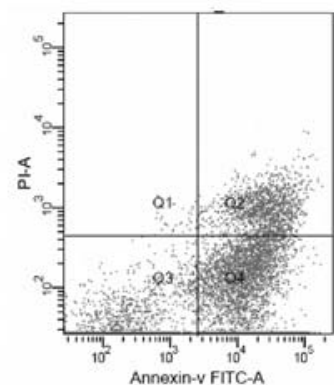

TNF- $\alpha+P D 98059$

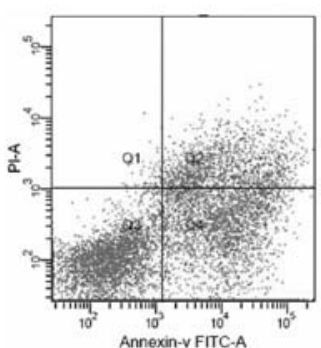

TNF- $\alpha+B K+P D 98059$

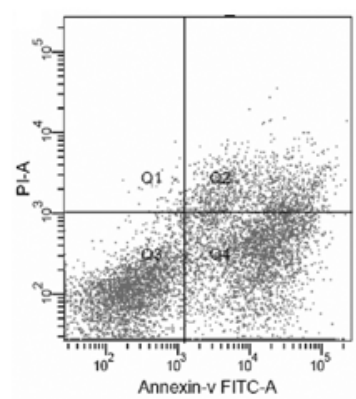

TNF- $\alpha+B K+L Y 294002$
B

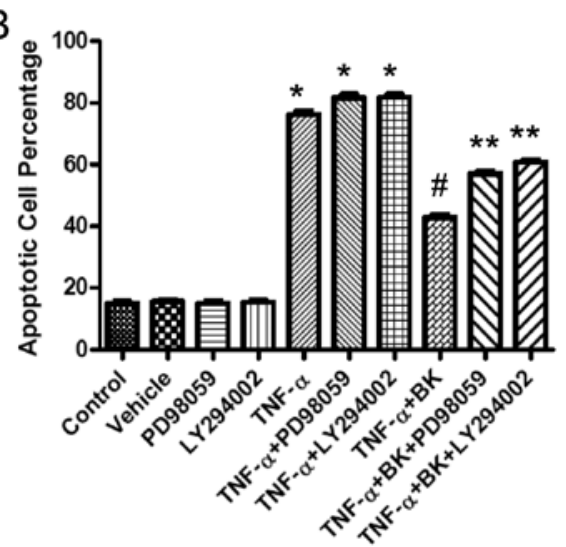

Figure 4. Possible mechanism of the effects of exogenous bradykinin (BK) on TNF- $\alpha$-induced apoptosis. (A) Representative results from three independent experiments evaluating the effects of signaling pathway inhibitors on TNF- $\alpha$-induced apoptosis in NIT-1 cells. Cells were incubated in the presence/absence of inhibitors of MEK (PD98059) or PI3K (LY294002) for 30 min prior to BK treatment, and then TNF- $\alpha$ was added for $24 \mathrm{~h}$. (B) Quantification of the ratio of apoptotic to total cells in panel A. Values shown are the means \pm SEM from three independent experiments. ${ }^{*} \mathrm{P}<0.05$ vs. control; ${ }^{*} \mathrm{P}<0.05$ vs. TNF- $\alpha$; ${ }^{* * *} \mathrm{P}<0.05$ vs. TNF- $\alpha+B K$.

In order to determine the optimal concentration of bradykinin to use in subsequent experiment, the effects of different concentrations of bradykinin (from $10^{-6}$ to $10^{-4} \mathrm{M}$ ) on TNF- $\alpha$ induced decreases in NIT-1 cell viability were examined.
TNF- $\alpha(100 \mathrm{ng} / \mathrm{ml})$ reduced NIT-1 cells viability, and $10^{-6} \mathrm{M}$ bradykinin did not prevent this decrease. Interestingly, $10^{-5} \mathrm{M}$ bradykinin markedly prevented NIT-1 cell viability decrease $(\mathrm{P}<0.05)$, compared with that of $10^{-6} \mathrm{M}$ bradykinin; however, 
A

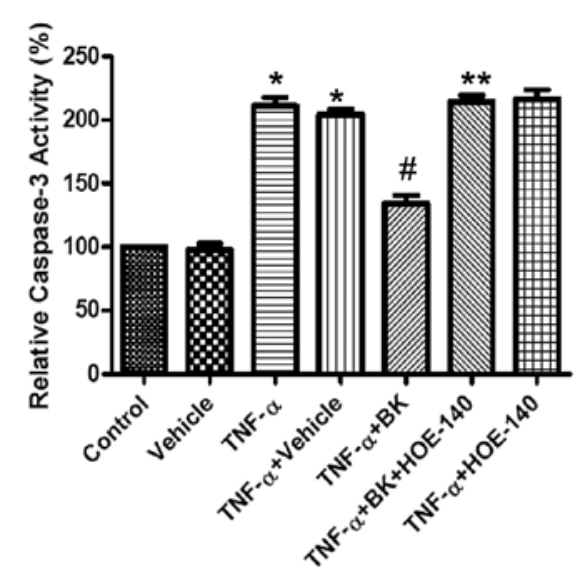

B

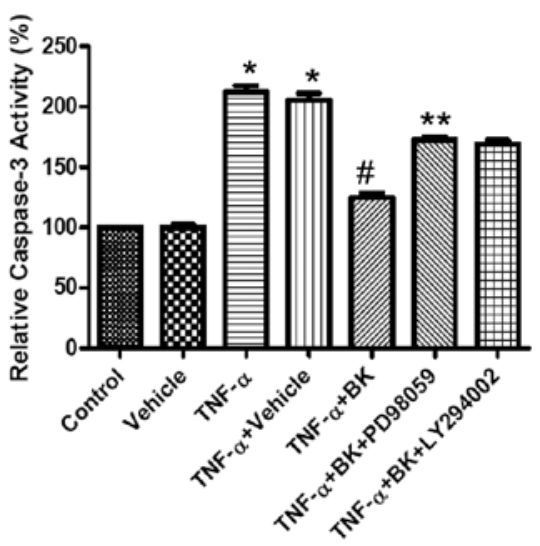

Figure 5. Exogenous BK inhibits caspase-3 activity. (A) NIT-1 cells were treated with $1 \%$ glacial acetic acid, TNF- $\alpha$ (100 ng/ml), BK (10-5 M) with/without HOE-140 $\left(10^{-5} \mathrm{M}\right)$, as indicated for $24 \mathrm{~h}$, and then caspase-3 activity was measured. Values are the mean $\pm \mathrm{SEM}$ from three independent experiments. ${ }^{*} \mathrm{P}<0.05$ vs. control; ${ }^{~} \mathrm{P}<0.05$ vs. TNF- $\alpha$; ${ }^{* *} \mathrm{P}<0.05$ vs. TNF- $\alpha+\mathrm{BK}$. (B) Cells were incubated with inhibitors of MEK (PD98059) or PI3K (LY294002) for 30 min prior to BK treatment, and then TNF- $\alpha$ was added to induce apoptosis. Values shown are the mean \pm SEM from three independent experiments. ${ }^{*}<0.05$ vs. control; ${ }^{\#} \mathrm{P}<0.05$ vs. TNF- $\alpha ;{ }^{* *} \mathrm{P}<0.05$ vs. TNF- $\alpha+\mathrm{BK}$.

$10^{-4} \mathrm{M}$ bradykinin did not show further inhibition on the NIT-1 cell viability reduction induced by TNF- $\alpha$. Thus, $10^{-5} \mathrm{M}$ was considered the best bradykinin concentration to be used in the subsequent experiments.

Bradykinin prevents NIT-1 cell viability reduction via the B2 bradykinin receptor. In order to determine the bradykinin receptor involved in this study, a B2 receptor antagonist HOE-140 was used. The optical density $(570 \mathrm{~nm})$ in the TNF- $\alpha$ group was significantly lower $(\mathrm{P}<0.05)$ to that in vehicle group (Fig. 2). Compared with that in the TNF- $\alpha$ group, the optical density $(570 \mathrm{~nm})$ in TNF- $\alpha+\mathrm{BK}$ group was significantly higher $(\mathrm{P}<0.05)$. Interestingly, the effect of $\mathrm{BK}$ on $\mathrm{TNF}-\alpha$-induced viability decrease was completely prevented by co-treatment with HOE-140 $(\mathrm{P}<0.05)$, suggesting that this effect of BK was $\mathrm{B} 2$ receptor-dependent. These data indicated that $\mathrm{BK}$ inhibited NIT- 1 cells viability reduction induced by TNF- $\alpha$ via the B2 bradykinin receptor.

Exogenous BK attenuates TNF- $\alpha$-induced apoptosis in NIT-1 cells. The effect of exogenous BK on NIT-1 cell viability was evaluated by flow cytometry. Cells exhibiting positive staining for Annexin V and negative staining for PI were considered apoptotic. As shown in Fig. 3, the vehicle for TNF- $\alpha$ (PBS) had no effect on NIT-1 cell survival. A significant increase in the percentage of apoptotic cells was observed after TNF- $\alpha$ treatment. Co-treatment with $\mathrm{BK}$ significantly reduced the percentage of apoptotic cells caused by TNF- $\alpha$ treatment, while the effect of BK on TNF- $\alpha$-induced apoptosis was completely prevented by co-treatment with HOE-140 $(\mathrm{P}<0.05)$, suggesting that this BK effect was B2 receptor-dependent. The data indicate that BK inhibited the TNF- $\alpha$-induced effects on NIT-1 cell apoptosis via the $\mathrm{B} 2$ receptor.

We also used inhibitors of various cell signaling pathways to determine the mechanisms of action of BK on TNF- $\alpha$ induced apoptosis in NIT-1 cells. As shown in Fig. 4, the effect of BK on TNF- $\alpha$-induced apoptosis was partially prevented by co-treatment with PD98059 (a MEK inhibitor) or LY294002 (a PI3K inhibitor), suggesting that this effect of BK was MEKand PI3K-dependent.

Exogenous BK inhibit caspase-3 activity. The effect of BK on the apoptosis of NIT-1 cells was further investigated by monitoring caspase-3 activity, which is increased in apoptosis. Treatment with TNF- $\alpha$ significantly increased caspase-3 activity in NIT-1 cells (Fig. 5). Importantly, TNF- $\alpha$-enhanced caspase-3 activity was suppressed by BK (Fig. 5). The effect of BK on caspase-3 activity was attenuated in the presence of HOE-140, PD98059 or LY294002 (Fig. 5), further confirming that the effect of $\mathrm{BK}$ on apoptosis occurs via the $\mathrm{B} 2$ receptor and its downstream MAPK and PI3K/AKT signaling pathways.

$B K$ inhibits the TNF- $\alpha$-induced downregulation of Bcl-2 and Bcl-xL as well as upregulation of Bax in NIT-1 cells. As expected, treatment with TNF- $\alpha$ downregulated Bcl-2 and $\mathrm{Bcl}-\mathrm{xL}$ protein expression and upregulated Bax protein expression, and BK caused significant increases in Bcl-2 protein expression at baseline. These changes were prevented by the addition of BK (Fig. 6). Interestingly, treatment with HOE-140 completely blocked the BK-induced upregulation of $\mathrm{Bcl}-2$ and Bcl-xL expression levels as well as downregulation of Bax protein expression levels. Treatments with PD98059 or LY294002 partially blocked the BK-induced upregulation of Bcl-2 and Bcl-xL expression levels as well as downregulation of Bax protein expression levels as shown in Fig. 6. Together, these findings suggest that the anti-apoptotic effect of exogenous BK in NIT-1 cells is likely mediated via induction of $\mathrm{Bcl}-2$ and Bcl-xL expression as well as downregulation of Bax expression. MEK- and PI3K are involved in this process.

Effect of BK on phosphorylated ERK1/2, PI3K and phosphorylated Akt expression. To further clarify the potential mechanisms underlying the observed effects of BK on TNF- $\alpha$ induced NIT-1 cell apoptosis, expression levels of a variety of intracellular signaling pathway proteins were investigated. As shown in Fig. 7, TNF- $\alpha$ significantly reduced levels of 
A

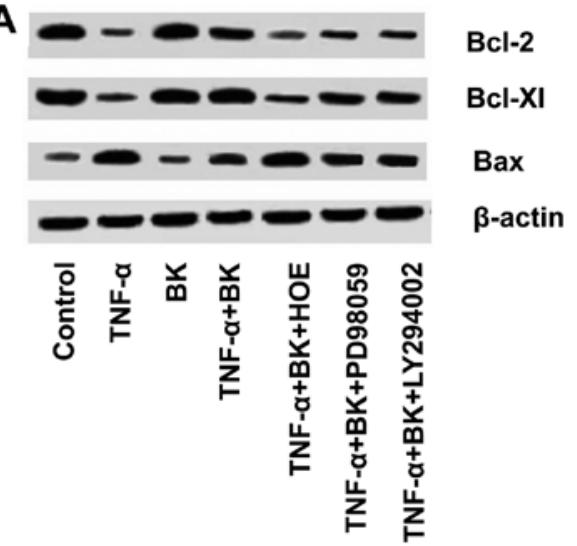

B

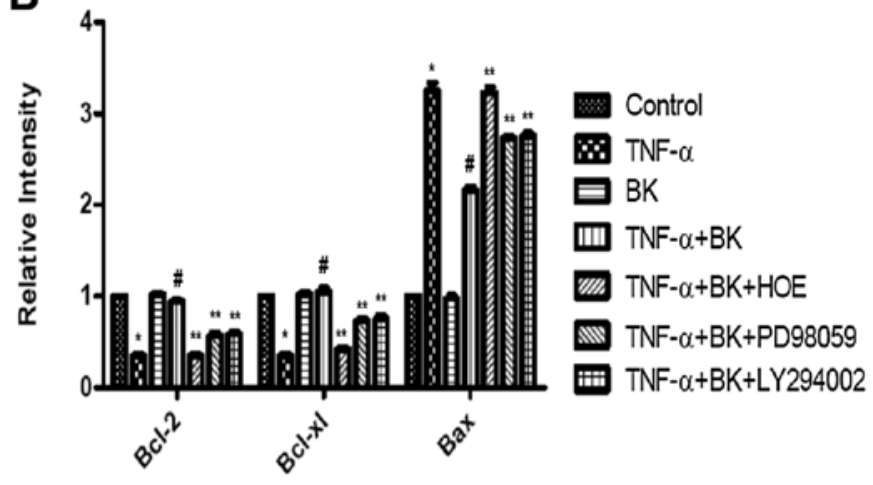

Figure 6. Exogenous bradykinin (BK) inhibits TNF- $\alpha$-induced downregulation of Bcl-2 and Bcl-xL as well as upregulation of Bax. Protein levels of Bcl-2, $\mathrm{Bcl}-\mathrm{xL}$ and Bax were determined by western blot analysis and normalized to $\beta$-actin expression. (A) Representative Bcl-2, Bcl-xL and Bax expression determined by western blot analysis. (B) Quantitative analysis of Bcl-2, Bcl-xL and Bax expression levels in NIT-1 cells, normalized by corresponding actin expression levels. Values are mean \pm SEM from three independent experiments. ${ }^{*} \mathrm{P}<0.05$ vs. control; ${ }^{*} \mathrm{P}<0.05$ vs. TNF- $\alpha ;{ }^{* *} \mathrm{P}<0.05$ vs. TNF- $\alpha+\mathrm{BK}$.

A

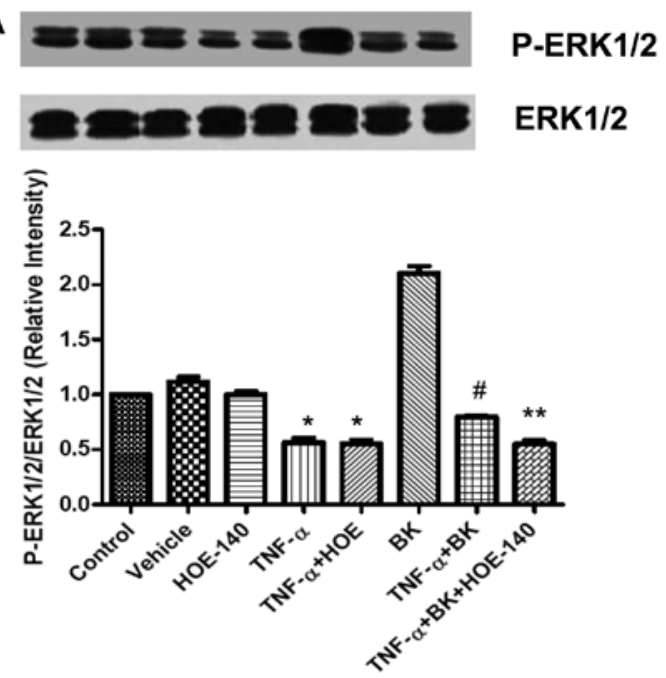

C

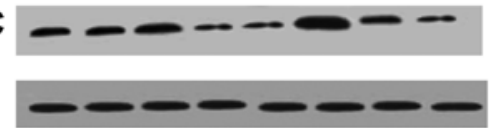

P-AKT

\section{AKT}

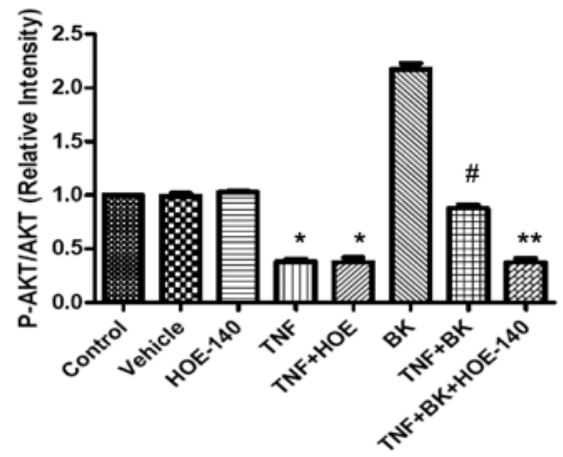

phosphorylated ERK1/2 (P-ERK1/2; Fig. 7A), PI3K (Fig. 7B) and phosphorylated AKT (P-AKT; Fig. 7C). Addition of BK reversed all of these changes, thus confirming that $\mathrm{BK}$ is involved in the activation of ERK1/2 and PI3K/AKT in NIT-1 cells.
B
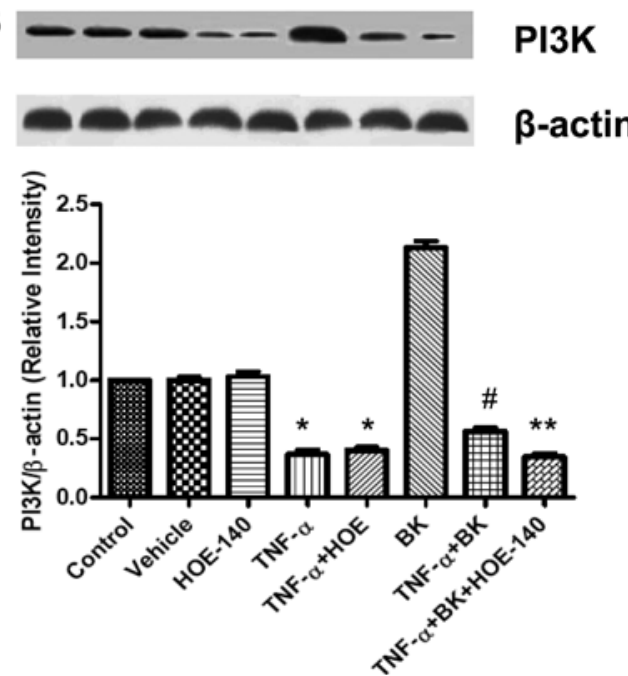

Figure 7. Effect of exogenous BK on phosphorylated ERK1/2, PI3K and AKT expression. Phosphorylated ERK1/2, PI3K and AKT expression levels were determined by western blot analysis and normalized to their corresponding controls. (A) Phosphorylated ERK1/2 and total ERK1/2 expression. (B) PI3K and $\beta$-actin expression. (C) Phosphorylated AKT and total AKT expression. Values are the mean \pm SEM from three independent experiments. ${ }^{*} \mathrm{P}<0.05 \mathrm{vs}$. control; ${ }^{\#} \mathrm{P}<0.05$ vs. TNF- $\alpha ;{ }^{* *} \mathrm{P}<0.05$ vs. TNF- $\alpha+\mathrm{BK}$.

\section{Discussion}

In this study, we demonstrated that exogenous BK significantly protected NIT-1 cells from TNF- $\alpha$-induced apoptosis via the MEK/MAPK and PI3K/Akt signaling pathways in vitro. The 
anti-apoptotic effect of BK was likely mediated via the induction of Bcl-2 and Bcl-xL expression as well as downregulation of Bax expression.

Previous data indicated that the kallikrein kinin system played critical roles in tissue cell survival. Tissue kallikrein infusion prevents cardiomyocyte apoptosis after myocardial infarction, and more importantly improves cardiac function, normalizes left ventricular wall thickness and decreases monocyte/macrophage infiltration in the infarct heart (10). Kinin infusion can directly protect against salt-induced renal injury without blood pressure reduction by inhibiting apoptosis (11). Bradykinin has been shown to regulate smooth muscle cells survival induced by angiotensin II (12). Our previous study showed that human tissue kallikrein overexpression decreased cell apoptosis in the target organs of spontaneous hypertensive rats and also inhibited lipopolysaccharide (LPS)-induced HEK 293 apoptosis (13). Tissue kallikrein and bradykinin receptors were constitutively expressed in pancreatic islets $(14,15)$. TNF- $\alpha$ is known to induce apoptosis of NIT-1 cells, a pancreatic $\beta$-cell line isolated from transgenic NOD/Lt mice (16). In this study, exogenous bradykinin significantly prevented NIT-1 cells apoptosis induced by TNF- $\alpha$, suggesting bradykinin is likely to exert important roles on pancreatic islet survival.

Apoptosis of pancreatic $\beta$-cells is critical in both the development of diabetes and in the failure of islet transplantation. Chronic exposure to high glucose and fatty acid levels induces $\beta$-cell apoptosis, leading to the exacerbation of type 2 diabetes (17). Overexpression of anti-apoptotic Bcl-2 or loss of pro-apoptotic Bax can partially rescue $\beta$-cells from death receptor-induced apoptosis (18). BK protects the viability of the microvascular endothelium exposed to the necrotic and apoptotic cell death inducers $\mathrm{H}_{2} \mathrm{O}_{2}$ and LPS via upregulation of Bcl-2 (19). The kallikrein gene transfer provides neuroprotection against cerebral ischemia injury by enhancing glial cell survival and inhibiting apoptosis through suppression of oxidative stress and activation of the Akt-Bcl-2 signaling pathway (20). These data indicate that BK can increase tissue cell survival at least in part by upregulation of Bcl-2 expression. In this study, exogenous BK markedly inhibited NIT-1 cell apoptosis induced by TNF- $\alpha$, and Bcl-2 and Bcl-xL expression was decreased in NIT-1 cells treated with TNF- $\alpha$. In contrast, Bax expression was increased in NIT-1 cells treated with TNF- $\alpha$. Interestingly, addition of BK significantly prevented the alterations in the Bcl-2, Bcl-xL and Bax expression levels described above. In summary, BK prevented NIT-1 cell apoptosis at least in part via the upregulation of Bcl-2 and Bcl-xL expression as well as by the downregulation of Bax expression.

Previous data demonstrated that bradykinin has two receptors, B1 and B2. Bradykinin B1, whose expression is induced by tissue damage, seem to have mostly noxious effects, whereas the constitutively expressed B2, when activated, exerts mostly beneficial actions. Accumulating evidence in the literature suggests that the $\mathrm{B} 2$ receptor has an important role in the homeostasis of endocrinology (21). Diabetic nephropathy is markedly enhanced in mice lacking the bradykinin B2 receptor (22), and similarly pharmacological blockade of the B2-kinin receptor reduces renal protective effect of the angiotensin-converting enzyme inhibition (ramipril) in the $\mathrm{db} / \mathrm{db}$ mouse model (23). These data indicate that bradykinin B2 receptors could act as a therapeutic target in diabetic nephropathy $(24,25)$. In this study, the bradykinin B2 receptor antagonist HOE-140 significantly and completely blocked the inhibitory effects of BK on NIT-1 cell apoptosis induced by TNF- $\alpha$, suggesting that the BK B2 receptor is critical for the protective effects of BK on NIT-1 cells apoptosis.

The p42/44 MAPK and PI3K/AKT signaling pathways are known to regulate $\beta$-cell replication (26) and $\beta$-cell mass and function (27). Kallikrein/kinin protects against cardiomyocyte apoptosis via Akt-Bad-14-3-3 and Akt-GSK-3 $\beta$-caspase-3 signaling pathways (28), and similarly kallikrein gene transfer provides neuroprotection against cerebral ischemia injury by enhancing glial cell survival and migration and inhibiting apoptosis through activation of the Akt-Bcl-2 signaling pathway (20). Our data show that the effect of BK on TNF- $\alpha$ induced apoptosis was partially prevented by co-treatment with PD98059 or LY294002, suggesting that this effect of BK was MEK- and PI3K-dependent.

In conclusion, we have demonstrated that exogenous BK suppressed apoptosis of NIT-1 cells in vitro. The protective effects of exogenous BK on $\beta$-cell survival exert a broad spectrum of beneficial effects on $\beta$-cell function. Further investigation of this approach in the treatment of diabetes in humans is thus warranted.

\section{Acknowledgements}

This study was partially supported by funds from the Nature Science Foundation Committee project no. 81100085 and no. 30930039 .

\section{References}

1. Marceau F and Regoli D: Bradykinin receptor ligands: therapeutic perspectives. Nat Rev Drug Discov 3: 845-852, 2004.

2. Moreau ME, Garbacki N, Molinaro G, Brown NJ, Marceau F and Adam A: The kallikrein-kinin system: current and future pharmacological targets. J Pharmacol Sci 99: 6-38, 2005.

3. Kishi K, Muromoto N and Nakaya Y, et al: Bradykinin directly triggers GLUT4 translocation via an insulin-independent pathway. Diabetes 47: 550-558, 1998.

4. Campbell DJ, Kladis A and Zhang Y, et al: Increased tissue kallikrein levels in type 2 diabetes. Diabetologia 53: 779-785, 2010.

5. Kakoki M, Sullivan KA and Backus C, et al: Lack of both bradykinin B1 and B2 receptors enhances nephropathy, neuropathy, and bone mineral loss in Akita diabetic mice. Proc Natl Acad Sci USA 107: 10190-10195, 2010.

6. Zhao C, Wang P and Xiao X, et al: Gene therapy with human tissue kallikrein reduces hypertension and hyperinsulinemia in fructose-induced hypertensive rats. Hypertension 42: 1026-1033, 2003.

7. Pruneau D, Belichard P, Sahel JA and Combal JP: Targeting the kallikrein-kinin system as a new therapeutic approach to diabetic retinopathy. Curr Opin Investig Drugs 11: 507-514, 2010.

8. Wang H, Lin L and Jiang J, et al: Up-regulation of endothelial nitric-oxide synthase by endothelium-derived hyperpolarizing factor involves mitogen-activated protein kinase and protein kinase C signaling pathways. J Pharmacol Exp Ther 307: 753-764, 2003.

9. Xu X, Zhao CX and Wang L, et al: Increased CYP2J3 expression reduces insulin resistance in fructose-treated rats and $\mathrm{db} / \mathrm{db}$ mice. Diabetes 59: 997-1005, 2010.

10. Yao YY, Yin H, Shen B, Chao L and Chao J: Tissue kallikrein infusion prevents cardiomyocyte apoptosis, inflammation and ventricular remodeling after myocardial infarction. Regul Pept 140: 12-20, 2007.

11. Chao J, Li HJ and Yao YY, et al: Kinin infusion prevents renal inflammation, apoptosis, and fibrosis via inhibition of oxidative stress and mitogen-activated protein kinase activity. Hypertension 49: 490-497, 2007. 
12. Colie S, Pecher C, Girolami JP and Blaes N: Modulation by bradykinin and nitric oxide of angiotensin II-induced apoptosis in a vascular smooth muscle cell phenotype. Int Immunopharmacol 8: 231-236, 2008.

13. Yan JT, Wang T and Wang DW: Recombinant adeno-associated virus-mediated human kallikrein gene therapy protects against hypertensive target organ injuries through inhibiting cell apoptosis. Acta Pharmacol Sin 30: 1253-1261, 2009.

14. PetrakiCD,Karavana VN, Revelos KI,LuoLY and DiamandisEP Immunohistochemical localization of human kallikreins 6 and 10 in pancreatic islets. Histochem J 34: 313-322, 2002.

15. Araujo RC, Mori MA and Merino VF, et al: Role of the kinin B1 receptor in insulin homeostasis and pancreatic islet function. Biol Chem 387: 431-436, 2006.

16. Stephens LA, Thomas HE and Ming L, et al: Tumor necrosis factor- $\alpha$-activated cell death pathways in NIT-1 insulinoma cells and primary pancreatic $\beta$ cells. Endocrinology 140: 3219-3227, 1999.

17. Shirakawa J, Amo K and Ohminami H, et al: Protective effects of dipeptidyl peptidase-4 (DPP-4) inhibitor against increased $\beta$ cell apoptosis induced by dietary sucrose and linoleic acid in mice with diabetes. J Biol Chem 286: 25467-25476, 2011.

18. McKenzie MD, Carrington EM and Kaufmann T, et al: Proapoptotic BH3-only protein Bid is essential for death receptorinduced apoptosis of pancreatic beta-cells. Diabetes 57: 1284-1292, 2008.

19. Bovenzi V, Savard M, Morin J, Cuerrier CM, Grandbois M and Gobeil FJ: Bradykinin protects against brain microvascular endothelial cell death induced by pathophysiological stimuli. J Cell Physiol 222: 168-176, 2010.
20. Xia CF, Yin H, Borlongan CV, Chao L and Chao J: Kallikrein gene transfer protects against ischemic stroke by promoting glial cell migration and inhibiting apoptosis. Hypertension 43: 452-459, 2004.

21. Manolis AJ,Marketou ME, Gavras I and Gavras H:Cardioprotective properties of bradykinin: role of the $\mathrm{B}(2)$ receptor. Hypertens Res 33: 772-777, 2010.

22. Kakoki M, Takahashi N, Jennette JC and Smithies O: Diabetic nephropathy is markedly enhanced in mice lacking the bradykinin B2 receptor. Proc Natl Acad Sci USA 101: 13302-13305, 2004.

23. Buleon M, Allard J and Jaafar A, et al: Pharmacological blockade of B2-kinin receptor reduces renal protective effect of angiotensinconverting enzyme inhibition in $\mathrm{db} / \mathrm{db}$ mice model. Am J Physiol Renal Physiol 294: F1249-F1256, 2008

24. Doggrell SA: Bradykinin B2 receptors as a target in diabetic nephropathy. Curr Opin Investig Drugs 7: 251-255, 2006.

25. Doggrell SA: Bradykinin B2 receptors - a target in diabetic nephropathy. Expert Opin Ther Targets 9: 411-414, 2005.

26. Friedrichsen BN, Neubauer N and Lee YC, et al: Stimulation of pancreatic beta-cell replication by incretins involves transcriptional induction of cyclin D1 via multiple signalling pathways. J Endocrinol 188: 481-492, 2006.

27. Elghazi L, Rachdi L, Weiss AJ, Cras-Meneur C and BernalMizrachi E: Regulation of beta-cell mass and function by the Akt/protein kinase B signalling pathway. Diabetes Obes Metab 9 (Suppl 2): 147-157, 2007.

28. Yin $\mathrm{H}$, Chao $\mathrm{L}$ and Chao $\mathrm{J}$ : Kallikrein/kinin protects against myocardial apoptosis after ischemia/reperfusion via Akt-glycogen synthase kinase-3 and Akt-Bad.14-3-3 signaling pathways. J Biol Chem 280: 8022-8030, 2005. 